\title{
AQUATIC ECOSYSTEM HEALTH ASSESSMENT OF THE ATHABASCA RIVER MAINSTEM OIL SANDS AREA USING WHITE SUCKER HEALTH
}

\author{
MARK E. MCMASTER, GERALD R. TETREATULT, THOMAS CLARK, JIM BENNETT, \\ JESSIE CUNNINGHAM \& MARLENE EVANS \\ Environment and Climate Change Canada, Burlington, Canada
}

\begin{abstract}
The Governments of Canada and Alberta designed an environmental monitoring plan for the lower Athabasca River between Fort McMurray and its confluence with Lake Athabasca. This plan, known as the Joint Oil Sands Monitoring Plan (JOSM), included monitoring aquatic ecosystem health with a focus on wild fish in the mainstem of the Athabasca River. The fish health program for JOSM used endpoints developed through Canada's Environmental Effects Monitoring Programs for the pulp and paper and metal mining sectors under Canada's Fisheries Act. Fish can be sensitive to multiple stressors, are critical components of aquatic ecosystems, and have significant social and economic value. The objective of the fish component of the aquatic monitoring program was to provide necessary data and supporting information to address key questions regarding both environmental health of fish populations and fish health issues related to use and consumption. The JOSM mainstem program consisted of large bodied fish health assessments at five stations and small bodied fish health assessments at nine stations on the Athabasca River. The large bodied white sucker were sensitive indicators of fish health in the system as consistent changes in fish health downstream, within the oil sands deposit were documented. These differences were indicative of nutrient enrichment as white sucker had increased condition and increased levels of internal fat stores relative to fish upstream of the oil sands area. The fish biomarker, ethoxyresorufin-O-deethylase activity, was a good indicator of exposure to polycyclic aromatic hydrocarbons and indicated the potential for increased exposure to these compounds downstream of oil sands development. Tiers and triggers are being developed for the program to predict change into the future and to be used in management decisions for further development in the area.
\end{abstract}

Keywords: fish health, environmental effects monitoring, oil sands, growth, reproduction and survival, EROD, tiers and triggers.

\section{INTRODUCTION}

The fish program for JOSM focused on fish health endpoints in select sentinel species as differences in growth, reproduction, condition and survival put fish at risk. Knowing this level of risk is important for managing aquatic ecosystems and these requirements are mandated under the Fisheries Act in Canada. By associating changes in fish health with invertebrate biodiversity, water and sediment chemistry and toxicology, and with physical habitat measurements, this program was designed to produce an integrated assessment that determines whether ecological effects are occurring in response to oil sands developments [1].

Three major historical sampling programs provided valuable baseline fish data: Alberta Oil Sands Environmental Research Program (AOSERP 1970-1980), Northern Rivers Basin Study (NRBS 1991-1996) and Regional Aquatic Monitoring Program (RAMP 1997-2011). The JOSM fish health sampling program, where possible and practical, followed historical sampling methods and sites to provide comparable data, although fish health endpoints were not often measured. Some of the most applicable historic data were collected as part of specific research programs conducted through funding from the Program of Energy 
Research and Development (PERD) in the late 1990s [2]. Data collected through the JOSM program will be compared to these historical datasets to provide a longer temporal perspective wherever possible.

Given the limited fish health data for the LAR, the JOSM investigations were intended to provide information needed to assess monitoring designs identified in the Phase 2 Integrated Monitoring Plan for the Oil Sands [3]. More importantly, work presented here attempts to answer the strategic questions identified in the Phase 2 plan. Key questions for the environmental health of fish populations and fish health issues related to use and consumption included: 1 . What is the current status of fish health in the lower Athabasca Region? 2. Are there existing differences in fish health among sites in the lower Athabasca Region? 3. Are there any trends/changes in fish health relative to historical studies? 4. What are contaminant levels in fish? 5. Are there any predictive relationships between system drivers (including development stress) and variability within sites in fish responses? and 6. Is there evidence of cumulative effects of development on fish in the lower Athabasca Region [3]?

Designing and implementing a 'world class' effects monitoring program, as called for in the Phase 2 Integrated Monitoring Plan [3], brought many challenges related to a large northern system including high flow events, migratory fish species, low species richness, limited access and transportation on the river, habitat change upstream, and continual loss of reference areas to development. Fish health studies on the mainstem Athabasca River consisted of sampling two sentinel fish species at sites upstream outside of the oil sands deposit, sites within the deposit upstream of development, and in the deposit downstream of oil sands development (Fig. 1). The large-bodied white sucker (Catostomus commersoni) was sampled during the fall of each year as a sentinel species because sucker species are known to demonstrate high site fidelity outside their spring spawning migration which can be tens of kilometers [4]. Sucker species are benthic feeders and also provide potential linkages to the invertebrate community bioassessments. A second sentinel fish species, the trout perch (Percopsis omiscomaycus), was included as a small bodied fish with reduced mobility that uses a smaller spatial area relative to the sucker. Previous fish health work on the mainstem Athabasca also used a sucker species and trout perch as sentinel species [2]. The first three years of results from the white sucker health assessments are discussed here.

\subsection{Objectives}

This 3-year JOSM study aimed to develop a comprehensive and robust fish health monitoring program for the LAR mainstem. The studies examined whether methods developed for use in the pulp and paper and metal mining effluent regulations could be used to evaluate fish health in the Athabasca River. Baselines of fish health were developed in the LAR mainstem; the potential for development in the oil sands area to affect overall fish health was also assessed using the sentinel species approach.

\section{METHODS}

\subsection{Study design}

Adult fish survey sampling protocols under the Canadian Environmental Effects Monitoring (EEM) Programs for pulp and paper and metal mining sectors were used to assess fish health. Study design for the fish health work, wherever possible, focused on collecting fish within the river system upstream, outside of the oil sands deposit as a 


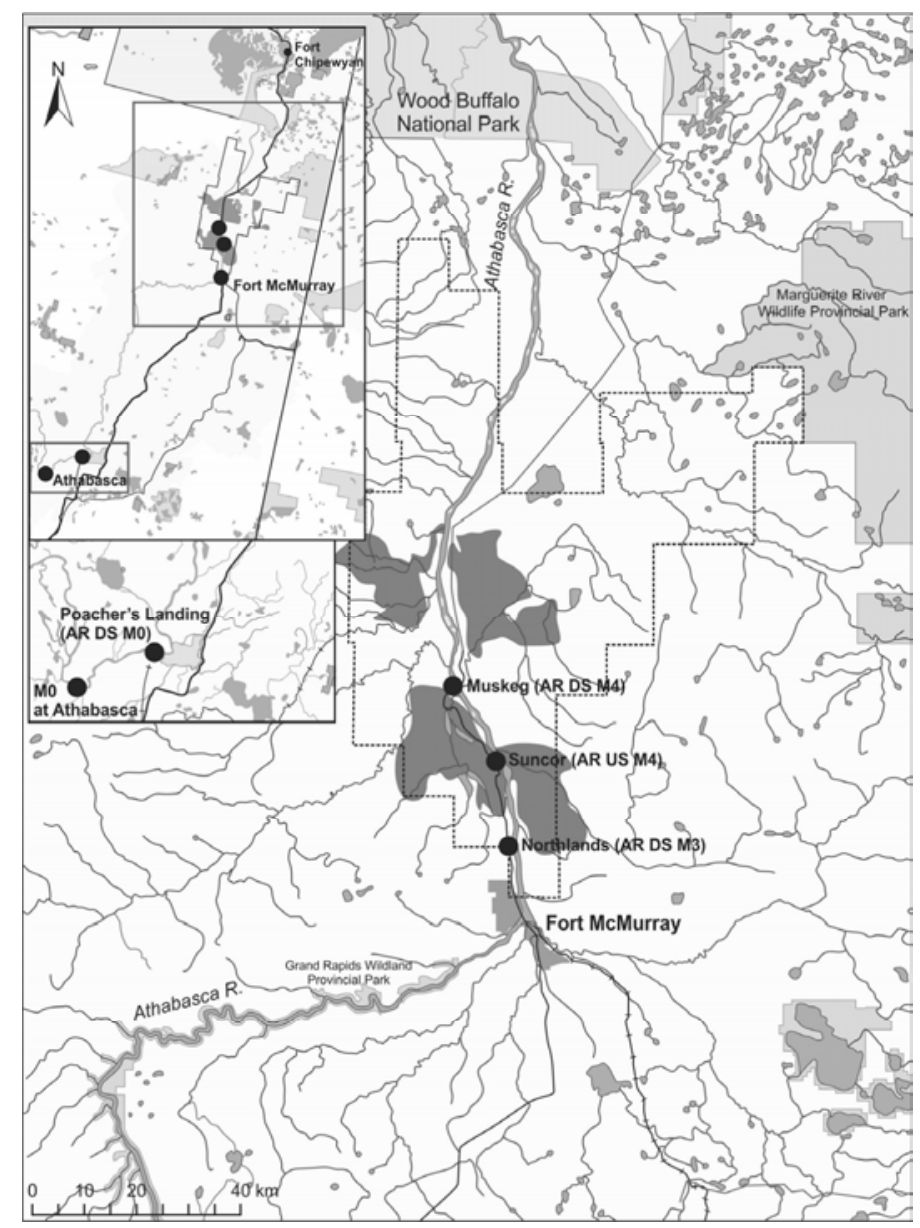

Figure 1: Map of fish collection sites.

reference site, within the deposit upstream of development, and within the deposit downstream of development (Fig. 1). The general study design for the fish health work was to collect 20 adult males and 20 adult females of the selected sentinel species for EEM endpoints [4]. Three years of data were to be collected at each location to establish variability in EEM endpoints and used to obtain baseline data for assessment of further development and to develop predictive relationships of fish health.

\subsection{Sampling sites and endpoints}

Fish from within the LAR mainstem (Fig. 1), were examined including two sites outside of the oil sands deposit (M0- Athabasca and AR DS M0 - Poacher's Landing), one site within the deposit upstream of development (AR DS M3 - Northlands) and two sites within the deposit and within oil sands development area (AR US M4- Suncor and AR DS M4Muskeg). Sampling for fish health was conducted during fall (once in a calendar year) in 
the months September-October. On the Athabasca River, white sucker were sampled as the large bodied species.

Boat electrofishing was used to collect white sucker for fish health and for contaminant analysis at all sites. Removal of stunned fish was accomplished using dip nets (approx. 0.5$\mathrm{cm}$ mesh size) followed by transportation to the on-site laboratory for processing. Detailed fish health assessments of individual fish included assessment of age, growth, condition, liver size and gonad size relative to body weight, and abnormalities assessments, all EEM endpoints used in the monitoring plans [4], [5]. Measurement of hepatic mixed-function oxygenase (MFO) activity as an indicator of exposure to pulp mill effluents, PCBs, PAHs, and some pesticides using ethoxyresorufin-O-deethylase (EROD) methods of Van den Heuvel et al. [6] and abnormalities for histological evaluation was conducted [7]. Liver samples in white sucker were collected for liver tumor assessments while muscle and liver tissue were collected for contaminant (PAH's and alkylated PAH's) analyses [8]. White sucker were also rated on visceral lipid stores using a subjective fat index ranging from 1-5 adapted from Munkittrick and Dixon [9].

\subsection{Statistical methods}

Within year comparisons: ANCOVA was used to compare EEM endpoints of condition of the fish (length versus body weight relationships), gonadosomatic indices (gonad weight versus body weight), and liver somatic indices (liver weight versus body weight) among sites and pairwise comparisons were used to identify site differences. ANOVA was used to compare EEM endpoints of weight and length of fish among sites following checks for homogeneity of variances and normally of the data. Non-parametric Kruskal-Wallis analysis was used to compare MFO activity and the EEM endpoint of age in fish among sites.

Comparisons between years: Although the design of the first three years of the JOSM fish program was to generate data to develop baseline conditions for future development, it was important to determine if differences exist among sites within year and if these differences were consistent between years of collection. EEM programs are designed to first evaluate site differences. In the next sampling period, the objective is to confirm responses seen in the previous year of sampling [4]. As three years of data were collected, response patterns were compared among the three years of collections and assessments made as to whether the changes found were the same, getting better or getting worse. Through the EEM programs for pulp and paper and metal mining, critical effect sizes have been developed and were applied here for decision endpoints and for assessing natural background variability [4]. For white sucker, average of the means for the upstream reference sites over time were calculated and critical effect sizes used from these means to assess change at downstream sites. All raw data can be found at [10] and summary tables of data are presented in McMaster et al. [8].

\section{RESULTS}

In 2011, white sucker were collected from four sites on the Athabasca River (Fig. 1 - site M0 was not sampled in 2011). Male white sucker captured within the deposit were older, longer, heavier, and had increased condition relative to the upstream white sucker captured outside of the deposit $(\mathrm{p}<0.05$, Table 1). These fish also had increased internal fat stores in the body cavity around the intestines and liver $(\mathrm{p}<0.05)$. Male white sucker downstream of development also grew faster with increased length and weight at any given age $(p<0.05$, Table 1) relative to upstream reference males. Male white sucker within the deposit had 
Table 1: Summary of differences in fish parameters and EROD analysis among sites within the Athabasca River for male white sucker. " 0 " indicate no statistical difference from reference sites. Blue arrows indicate a positive increase and red arrows indicate a negative response relative to the reference sites. Asterisks indicate interactions in the relationships between sites.

\begin{tabular}{|c|c|c|c|c|c|c|c|c|c|c|}
\hline Year & Species & Site & Site Type & Sex & Age & Growth & Condition & GSI & LSI & EROD \\
\hline 2011 & White sucker & $\begin{array}{l}\text { AR DS M0 } \\
\text { AR DS M3 } \\
\text { AR US M4 } \\
\text { AR DS M4 }\end{array}$ & $\begin{array}{l}\text { Reference } \\
\text { Deposit } \\
\text { Development } \\
\text { Development }\end{array}$ & M & & 0 & & $\begin{array}{l}0 \\
0 \\
0\end{array}$ & 0 & \\
\hline 2012 & White sucker & $\begin{array}{l}\text { M0 / AR DS M0 } \\
\text { AR DS M3 } \\
\text { AR US M4 } \\
\text { AR DS M4 }\end{array}$ & $\begin{array}{l}\text { Reference } \\
\text { Deposit } \\
\text { Development } \\
\text { Development }\end{array}$ & & 0 & 0 & & $\begin{array}{l}0 \\
0 \\
0\end{array}$ & 10 & \\
\hline 2013 & White sucker & $\begin{array}{l}\text { M0 / AR DS M0 } \\
\text { AR DS M3 } \\
\text { AR US M4 } \\
\text { AR DS M4 }\end{array}$ & $\begin{array}{l}\text { Reference } \\
\text { Deposit } \\
\text { Development } \\
\text { Development }\end{array}$ & & $\begin{array}{l}0 \\
0 \\
0\end{array}$ & $\begin{array}{l}0 \\
0 \\
0\end{array}$ & $\begin{array}{l}0 \\
0 \\
0\end{array}$ & $\begin{array}{l}{ }^{*} 0 \\
0 \\
0\end{array}$ & $\begin{array}{l}0 \\
0 \\
0\end{array}$ & \\
\hline
\end{tabular}

increased hepatic MFO activity using EROD methods relative to the upstream site $(\mathrm{p}<0.001$, Table 1), with no significant differences among sites within the deposit and downstream of development.

In 2012, an additional reference location (M0 Athabasca) was added for fish health within the JOSM program (Fig. 1). This site was used for water quality in the JOSM program and is upstream of the municipal wastewater discharge for the town of Athabasca. It serves as the upper most reference site for white sucker health as well as a reference location to evaluate the potential influence pulp mill discharge has on fish health at the AR DS M0 location. All male fish EEM endpoints were similar between the two upstream locations in 2012 so were pooled for comparison. Male white sucker downstream of development were older, longer and heavier than reference fish, with increased internal fat stores and increased condition ( $\mathrm{p}<0.05$, Table 1). In 2012, the deposit site AR DS M3 was somewhat intermediate in most of the male white sucker health endpoints. Similar to the white sucker collections in 2011, the major response pattern was one of nutrient enrichment as fish downstream of development were longer, heavier and had increased condition and internal fat stores. EROD activity was similar to 2011 as male white sucker within the deposit were induced relative to upstream reference males with no differences from deposit to downstream of development (Table 1).

Generally, in 2013, male white sucker collected within the deposit were comparable to upstream reference fish. Male white sucker collected at the furthest downstream site, AR DS M4 were often significantly different than the M0 upstream reference site. However, these fish were not different than those collected downstream of the pulp mill discharge outside of the deposit at AR DS M0 (Table 1). Male white sucker EROD activity was still induced at all sites within the deposit $(\mathrm{p}<0.001)$ similar to the two previous years.

Male white sucker response patterns using EEM health endpoints and EROD as an indicator of exposure show exposure appears to be very similar among the three years of baseline white sucker collections but that fish health responses vary between years, with male white sucker downstream of development generally showing the most responses (Table 1). In 2011, males from the site within the deposit upstream of development were 
similar to fish collected downstream of development. In 2012, they were intermediate between upstream reference and downstream development. Male fish from all sites in 2013 were similar, demonstrating potential improvements in fish health within the deposit and downstream of development in 2013.

In 2011, female white sucker collected at all three sites within the deposit had increased condition factor and levels of internal fat around the intestines and liver $(\mathrm{p}<0.05$, Table 2$)$. Female white sucker at the furthest development downstream site (AR DS M4) were also longer, heavier and had increased growth rates, and invested more energy into reproductive development $(p<0.05)$. Female white sucker in 2011 demonstrated more of a graded MFO induction, with AR DS M0 being lowest, induced at AR DS M3, highest at the AR US M4 site, and reduced somewhat at the AR DS M4 location ( $p<0.05$, Table 2).

In 2012, similar to male white sucker, all fish EEM health endpoints were comparable between the two upstream locations for female white sucker. Female white sucker were older at the downstream locations within the deposit relative to both reference sites and generally longer, heavier and with increased condition similar to 2011, although only significant at the furthest downstream development site (AR DS M4) $(\mathrm{p}<0.05$, Table 2). No significant differences in female white sucker growth or internal fat were found, although trends to increased internal fat were evident downstream of development in 2012. Female EROD activity was increased in all three locations within the deposit with no differences downstream of development (Table 2).

Generally, in 2013, female white sucker collected within the deposit were similar to upstream reference fish. Female white sucker were similar in all EEM health endpoints, although liver size did differ significantly between sites, no deposit or development relationship was evident. Similar to 2012, EROD activity was induced in female white sucker collected within the deposit with no differences in induction between the AR DS M3 site upstream of development and the two sites downstream of development (Table 2).

Similar to male white sucker, although exposure appears to be very similar among the three years of baseline white sucker collections (EROD levels), fish health responses vary between years with female white sucker downstream of development generally showing most responses. In 2011 and 2012, female white sucker within the deposit upstream of development appear intermediate to the responses downstream of development. In 2013, females from all sites were similar, demonstrating potential improvements in fish health within the deposit and downstream of development (Table 2).

\subsection{Natural background variability}

With three years of data (five collections from two upstream locations), it is possible to assess reference site variability and develop baselines for reference sites to compare differences in downstream fish to overall natural variability. As an example, male condition was used from the two upstream sites over the three-year period. Using these data, the mean male white sucker condition at the upstream sites was determined and then upper and lower limits set using both a critical effect size of 10\% and two SDs of the mean [4]. In 2011 and 2012, AR DS M4 male condition is above both the 10\% critical effect size and two standard deviations of the reference mean (Fig. 2). Although condition is also higher in 2013, these data are within reference site variability. Similar analysis can be completed with the other fish health endpoints, including age, growth, gonado - and liver somatic indices in both sexes. 
Table 2: $\quad$ Summary of differences in fish parameters and EROD analysis among sites within the Athabasca River for female white sucker. "0" indicate no statistical difference from reference sites. Blue arrows indicate a positive increase and red arrows indicate a negative response relative to the reference sites.

\begin{tabular}{|c|c|c|c|c|c|c|c|c|c|c|}
\hline Year & Species & Site & Site Type & Sex & Age & Growth & Condition & GSI & LSI & EROD \\
\hline 2011 & White sucker & $\begin{array}{l}\text { AR DS M0 } \\
\text { AR DS M3 } \\
\text { AR US M4 } \\
\text { AR DS M4 }\end{array}$ & $\begin{array}{l}\text { Reference } \\
\text { Deposit } \\
\text { Development } \\
\text { Development }\end{array}$ & $F$ & $\begin{array}{l}0 \\
0 \\
0\end{array}$ & 0 & & $\begin{array}{l}0 \\
0 \\
0\end{array}$ & $\begin{array}{l}0 \\
0 \\
0\end{array}$ & \\
\hline 2012 & White sucker & $\begin{array}{l}\text { M0 / AR DS M0 } \\
\text { AR DS M3 } \\
\text { AR US M4 } \\
\text { AR DS M4 }\end{array}$ & $\begin{array}{l}\text { Reference } \\
\text { Deposit } \\
\text { Development } \\
\text { Development }\end{array}$ & & 0 & $\begin{array}{l}0 \\
0 \\
0\end{array}$ & & $\begin{array}{l}0 \\
0 \\
0\end{array}$ & $\begin{array}{l}0 \\
0 \\
0\end{array}$ & \\
\hline 2013 & White sucker & $\begin{array}{l}\text { M0 / AR DS M0 } \\
\text { AR DS M3 } \\
\text { AR US M4 } \\
\text { AR DS M4 }\end{array}$ & $\begin{array}{l}\text { Reference } \\
\text { Deposit } \\
\text { Development } \\
\text { Development }\end{array}$ & & $\begin{array}{l}0 \\
0 \\
0\end{array}$ & $\begin{array}{l}0 \\
0 \\
0\end{array}$ & $\begin{array}{l}0 \\
0 \\
0\end{array}$ & $\begin{array}{l}0 \\
0 \\
0\end{array}$ & $\begin{array}{l}0 \\
0 \\
0\end{array}$ & \\
\hline
\end{tabular}

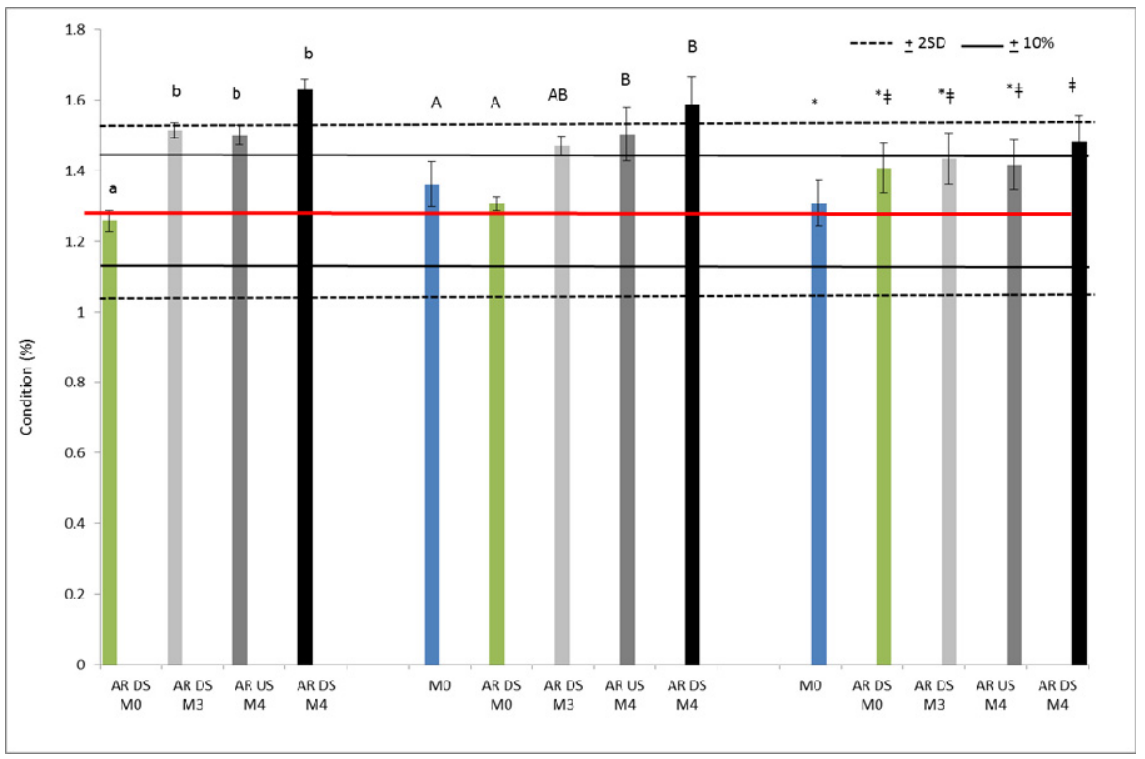

Figure 2: Male white sucker condition from sites collected on the Athabasca River in 2011-2013. Means \pm S.E. with the critical effects size of $10 \%$ and two standard deviations of the reference site means indicated.

\section{DISCUSSION}

Overall, white sucker were sensitive indicators of fish health in the system as consistent changes in fish health were documented downstream within the oil sands deposit in 2011 and 2012. These differences were indicative of nutrient enrichment, as white sucker have increased condition and increased levels of internal fat stores. Responses were confirmed in white sucker in the first two years of the studies similar to what is done in Canada's EEM 
programs [4]. Patterns of nutrient enrichment have also been found in fish downstream of some municipal sewage discharges and pulp and paper effluent discharges in Canada especially prevalent in receivers that are nutrient poor [11]. However, the third year of white sucker fish health studies indicated changes occurring with fish within the deposit, as condition factors were no longer different and improvements in excessive fat deposits in the body cavity were evident. The JOSM fish health program has moved from three intensive years of baseline data collection to a once every three-year, long-term monitoring program. It is recommended to evaluate whether improvements in fish health identified in year three are confirmed in the next sampling period. Arens et al. [12] collected spawning white sucker from the Muskeg River, a tributary of the Athabasca River very close to the AR DS M4 location, and also demonstrated increased energy storage in terms of condition factor and liver size relative to fish collected from a lake upstream of the oil sands deposit. They also demonstrated reduced investment of energy into reproductive development (gonad size and fecundity) which was not seen in the studies here. This may be due to the fact that this study collected resident fish from the Athabasca River in the fall of the year, and Arens et al. [12] collected fish during the spawning period in the spring. Earlier monitoring programs in the area collected fish community data on the mainstem Athabasca River as well as fish communities that use tributary streams for spawning in the spring (Regional Aquatic Monitoring Program). Arciszewski et al. [13] re-analysed the long term data set from the Athabasca River (1987-2014) and revealed increases in the lengths of white sucker and walleye and their relative abundances during the spring spawning season. These differences were not observed in surveys conducted in the summer and early fall suggesting that differences in the spring may be due to reduced fishing pressure in Lake Athabasca where these larger fish migrate into the Athabasca River and its tributaries to spawn [13]. Other changes in migratory fish communities have been documented using historic records of fish fence collections on the Muskeg River [14]. Overall, the total number of fish using the river to spawn changed significantly during the period of 1995 to 2006 with consistently lower numbers of Arctic grayling, longnose sucker and mountain whitefish. White sucker numbers also decreased initially then increased significantly in the late 2000s making up $99 \%$ of the sample collected. The white sucker collected in the late 2000s also demonstrated increased condition relative white sucker collected from this same location in earlier studies [14].

Hepatic EROD activity indicated exposure of fish to PAH-related compounds and suggested some potential increased exposure downstream of development. This was reflected best in PAH levels in white sucker liver tissue in both males and females with increased PAHs downstream of development [8]. Although fish health endpoints recovered somewhat in 2013, this was not evident in levels of induction in either male or female white sucker livers [8]. Ohiozebau et al. [15] also identified increased concentrations of PAHs in the bile of fish collected from Fort McKay which is closest to the Muskeg AR DS M4 site in the studies here. EROD activity was always highest at one of the deposit sites downstream of development with induction in fish from the deposit but upstream of development site (AR DS M3) often intermediate. Arens et al. [12] also found induced hepatic EROD activity in spawning white sucker collected from the Muskeg River compared to spawning fish collected from an upstream Calling Lake population. Similar fish health studies conducted on a tributary to the Athabasca River, the Steepbank River also demonstrated induced EROD activity in Slimy sculpin (Cottus cognatus) collected downstream of oil sands development relative to within the deposit upstream of development and at upstream reference locations [2]. Parrott et al. [16] more recently identified increased levels of PAHs and alkylated PAHs in snow collected on that and other 
tributaries in the development area of the oil sands which when exposed to fathead minnow embryos resulted in increased mortality. Although abnormalities were recorded for the white sucker from these studies, no increased levels of deformities were identified within the deposit or downstream of development [8].

The evaluation of site differences relative to overall upstream reference site variability has documented change in fish collected in the deposit and downstream of industrial activity that exceed defined critical effects sizes established in the Canadian EEM programs [4], [5]. These differences, however, were very much improved in 2013. The overall design of the EEM programs in Canada using fish health endpoints, starts with surveillance monitoring. The next cycle of data collection is a confirmation stage to determine whether changes documented in cycle 1 are confirmed in cycle 2 . If effects are confirmed and are outside of the critical effect sizes (CES) set within the program, focused studies are triggered looking at the magnitude and extent of the changes. If the effects exceed CES and getting worse, investigation of cause and investigation of solutions follow in the program [4], [5]. For white sucker health, the third year of data collection identified improvements in fish health within the oil sands deposit downstream of development. The next cycle of collections will now serve to confirm these improvements in fish health. Additional tools are being developed to assess change within and between sites within the oil sands area. With three years of data at individual sites, normal can be defined for that site over the three years of monitoring. To do this, a cumulative mean $\pm 2 \mathrm{SD}$ is calculated and then used to make more meaningful predictions of future observations as more data are added [17]. These tools should be used to make predictions of fish health into the future and to identify change within site and between sites in the oil sands area.

\section{ACKNOWLEDGEMENTS}

The authors would like to thank all who participated in fish health collections and lab work over several years: Mark Hewitt, Adrienne Bartlett, Dominique Turcotte, Alicia Mehlenbacher, Ross Neureuther, Christine Lavalle, Richard Frank, Nicholas Maya, Kazlyn Bonnor, Jennifer Ings, Deanna Murray, Katherine French, Lana Miller, Anthony Bauer, Shannon McFadden, Jonathon Keating, Kallie Shires, Meghan Bree, Michael Dunning, Mandeep Mann, Ola Oni, Tannis Neheli, Sorina Chiorean, and Daniel Byrne. Thank you to Hatfield Consultants for their collaborative efforts and great assistance helping work in such difficult environments.

\section{REFERENCES}

[1] Environment Canada, Integrated Monitoring Plan for the Oil Sands - Expanded Geographic Extent for Water Quality and Quantity, Aquatic Biodiversity and Effects, and Acid Sensitive Lake Component (En14-49/2011E-PDF ISBN 9781-100-18939-0), 2011.

[2] Tetreault, G.R., McMaster, M.E., Dixon, D.G. \& Parrott, J.L., Using reproductive endpoints in small forage fish species to evaluate the effects of Athabasca Oil Sands activities. Environmental Toxicology and Chemistry, 22(11), pp. 2775-2782, 2003.

[3] Doherty, C.A., Curry, R.A. \& Munkittrick, K.R., Spatial and temporal movements of white sucker: Implications for use as a sentinel species. Transactions of the American Fisheries Society, 139(6), pp. 1818-1827, 2010.

[4] Environment Canada, Pulp and Paper Environmental Effects Monitoring (EEM) Technical Guidance Document. National EEM Office, Environment Canada, Ottawa, Ontario, 2010. www.ec.gc.ca/eem/pdf_publications/English/TGD_e.pdf. 
[5] Environment Canada, Metal Mining Technical Guidance for Environmental Effects Monitoring. National EEM Office, Environment Canada, Ottawa, Ontario, 2012. www.ec.gc.ca/esee-eem/default.asp?lang=En\&n=AEC7C481-1.

[6] Van den Heuvel, M.R., Munkittrick, K.R., Stegeman, J.J. \& Dixon, D.G., Secondround interlaboratory comparison of hepatic ethoxyresorufin-O-deethylase activity in white sucker (Catostomus commersoni) exposed to bleached-kraft pulp mill effluent. Environmental Toxicology and Chemistry, 14(9), pp. 1513-1520, 1995.

[7] Blazer, V.S., Rafferty, S.D., Baumman, P.C., Smith, S.B. \& Obert, E.C., Assessment of the "fish tumors or other deformities" beneficial use impairment in brown bullhead (Ameiurus nebulosus): II. Liver neoplasia. Journal of Great Lakes Research, 35(4), pp. 527-537, 2009.

[8] McMaster, et al., Aquatic ecosystem health assessment of the Athabasca River mainstem and tributaries using fish health and fish and invertebrate toxicological testing. A technical synthesis report prepared for the Canada-Alberta Joint Oil Sands Monitoring Program, 2018.

[9] Munkittrick, K.R. \& Dixon, D.G., Growth, fecundity, and energy stores of white sucker (Catostomus commersoni) from lakes containing elevated levels of copper and zinc. Canadian Journal of Fisheries and Aquatic Sciences, 45, pp. 1355-1365, 1988.

[10] Environment Canada Joint Oil Sands Monitoring data portal. www.jointoilsandsmonitoring.ca/flex/index.html?lang=en.

[11] McMaster, et al., Detailed endocrine assessments of wild fish in the Northern River Basins, Alberta, in comparison to EEM monitored endpoints. Water Quality Research Journal of Canada, 40(3), pp. 299-314, 2005.

[12] Arens, C.J. et al., Population impacts in white sucker (Catostomus commersoni) exposed to oil sands-derived contaminants in the Athabasca river. Environmental Toxicology and Chemistry, 36(8), pp. 2058-2067, 2017. DOI: 10.1002/etc.3735.

[13] Arciszewski, T.J., Munkittrick, K.R., Kilgour, B.W., Keith, H.M., Linehan, J.E. \& McMaster, M.E., Increased size and relative abundance of migratory fishes observed near the Athabasca oil sands. Facets, 2, pp. 833-858, 2017. DOI: 10.1139/facets2017-0028.

[14] Schwalb, A.N., Alexander, A.C., Paul, A.J., Cottenie, K. \& Rasmussen, J.B., Changes in migratory fish communities and their health, hydrology and water chemistry in rivers of the Athabasca oil sands region: A review of historical and current data. Environmental Reviews, 23, pp. 1-18, 2015. DOI: 10.1139/er-20140065 .

[15] Ohiozebau, E. et al., Products of biotransformation of polycyclic aromatic hydrocarbons in fishes of the Athabasca/Slave river system, Canada. Environmental Geochemistry and Health, 38(2), pp. 577-591, 2015. DOI: 10.1007/s10653-0159744-6.

[16] Parrott, J.L. et al., Meltwater from snow contaminated by oil sands emissions is toxic to larval fish, but not spring river water. Science of the Total Environment, 625, pp. 264-274, 2017. DOI: 10.1016/j.scitotenv.2017.12.284.

[17] Arciszewski, T.J. \& Munkittrick, K.R., Development of an adaptive monitoring framework for long-term programs: An example using indicators in fish. Integrated Environmental Assessment and Management, 11(4), pp. 701-718, 2015. DOI: 10.1002/ieam.1636. 